\title{
On the Reform of Teaching Approaches to Circuit and the Improvement of Students' Individual Abilities
}

\author{
Wei Dongmei $^{\mathrm{a}}$, LI Jiyong ${ }^{\mathrm{b}}$, XIONG Xiaoping $^{\mathrm{c}}$, GONG Wenying $^{\mathrm{d}}$ and LI Hui ${ }^{\mathrm{e}}$ \\ Guangxi University, nanning, China \\ a349073356@qq.com, bji_yong_li@163.com, cxp_xiong@gxu.edu.cn, dwy_gong@gxu.edu.cn, \\ ehui_li@gxu.edu.cn
}

Keywords: circuit theory, teaching process, capability.

\begin{abstract}
This paper analyses the common disadvantages of circuit course teaching process, puts forward the philosophy that the cultivation of students' innovation ability, the students' diversified and personalized, the resistance capacity, self-discipline, and the awareness of fair competition shall all be melted into the teaching process.
\end{abstract}

\section{Introduction}

Circuit theory course is a required professional basic course at home and abroad for electrical engineering specialty. Its main task is to learn to analyze the basic method regarding computing circuit and preliminary experimental skills, and to lay a solid theoretical and practical foundation for electrical engineering students of all the professional courses and those engaged in engineering work and scientific research work after graduation. The importance of electric circuit theoretical courses to undergraduate students is self-evident. But for many years the following shortcomings have been existing among the traditional teaching with circuit both in content of courses setting and teaching process: (1) emphasis too much on theory, despise practical application, the alienation between theory education and engineering practice is serious; (2) emphasis too much on examination results, despise learning process, there are some inadequacy among teaching method and teaching means; (3) over emphasis on circuit theory and technology learning, neglect of individual ability. So how to avoid cramming, duck-fed teaching methods in circuit theory in the process of teaching, increase students' interest in learning, improve student learning initiative, to enable students to better grasp the basic knowledge of the basic circuit theory and application have been always in our minds and been our urgent research topic to work on. In addition, as eligible and quality university teachers, the responsibility required by our society is not only to impart knowledge to students, but also to teach them to behave, to improve their quality and ability as young citizens. The authors consider that the teaching process should be including the following aspects ${ }^{[1]-[4]}$.

\section{The developing and cultivating of students' practical ability and creative spirit shall be blended into the process of circuit theory teaching}

In the teaching process of circuit theory, in order to improve the students' practical ability and practice ability, allow the students return to the fields of engineering application, the teachings and its experiments should be well-designed, practical and operable. For example: (1) study of the controlled source circuit. We may put in a request, design a voltage (or current) source controlled by current or voltage with $\mathrm{K}$ as coefficient, provide some resistance components, operational amplifiers. The experiments, like circuit design and connect, self measurement of circuit wiring controlled, volt ampere characteristics, shall be designed and finished by the students themselves alone. (2) study of the gyrator. We too, can provide transformers, inductance or capacitance elements for the students and, ask them to design a gyrator with $r$ as rotary resistance, and the results should be tested through experiments by the students. (3) study of the ideal transformer and its coupled inductance element. A mutual inductance black box should be prepared, and the students are asked to identify the polarity end and, to measure the mutual inductance coefficient $\mathrm{M}$ etc.. There are many can be done in this 
regard, because of the limited space, we won't like to give any repetitive or trivial details. In order to highlight the importance of practical experiment results, more of which should be taken into account, in another word, practical grades shall take a relatively large proportion among the total.

In addition, in order to cultivate and develop the exploit ability and the innovation spirit, study for the sake of application, circuit course should add small designs or small papers as new teaching links. The topic can be wide and narrow. For example: circuit theory application in practice; the applications of circuit theorem in electronic circuit; a first-order circuit application in practice; two order circuit application in practice; the application of two port network in analyzed electronic circuit; the practical application of resonant circuit; the application of principles of improving power factor in power system; the aims of these designs are intent to make the students through extensive data queries, Internet browse realize the practical use of circuit theory. Narrow topic can be used as kinds of curriculum designs, for example: a design based on circuit theoretical principles of single-phase power into a three-phase power supply; the gyrator design based on the circuit theory; the design of impedance converter based on the principles of circuit theory; the design of point lines (car, motorcycle, water heater etc. ). The intention of these is to make the students through the designs and simulation, processes to achieve a combination of theory and practice. Course paper and design grades should be integrated into the students' learning achievement and be parts of the whole grades.

\section{The developing and cultivating of students' diversified and personalized shall be integrated into the process of circuit theory teaching}

Circuit theory teaching process, should include experimental operation, the midterm exam, attendance, small design courses and course work, class of exercises, in addition to these, besides teachers' lectures, these links, in line with the exerting initiative of students, should be arranged some time and contents for students to ask questions, to explain, to maximize themselves, and the project achievements should be regarded as parts of the whole achievement of students in the semester. This is the so-called "interaction" teaching mode. In the classroom teaching of circuit theory, "interaction" can exist in learning and guiding, concept formation or vice versa, the linking between theory and practice, logical reasoning and formulas derivations, and the concept summary and briefing of each chapter as well. For example, when teaching how to do the exercises, we can allow the teachers and students to do and explain some questions respectively, then ask other students to do the comments, it makes students more involve in and deepen the understanding of theoretical knowledge. On the new concept and new content, such as can be introduced, too, we may allow the students to explain the meaning and application of the concepts to the whole class first, then the teacher to do the correcting, summary, through which students could make further understanding to the boring circuit principles, replace the passive learning with active thinking. Compared the mode which regards teacher and text as center, concerned only unilateral and traditional circuit theory teaching method, to the mode of "interaction", the latter more reflects the innovation idea of "people-oriented" "study for the sake of practice" of higher education teaching and, can take students as the center during circuit theory teaching, changes the tendency of sheerly accepting the knowledge for students alone, and lays emphasis on discovery learning, inquiry learning, interactive learning.

\section{The developing and training of students' abilities to resist setbacks and frustration, compress shall be integrated into the process of circuit theory teaching}

The world we live in is far from "vacuum tube", life means we need to meet all kinds of people, and to deal with every hue, to do all kinds of challenging work, to encounter a variety of setbacks and difficulties. Who can guarantee that his life will ever filled with flowers and smiling, everything goes smoothly without up and down? Since some students, from cradle to grave, eating, drinking, shitting... all in all taken care by parents, led by the teachers in their studies, have never truly encountered setbacks and difficulties caused by real life, they acquired strong dependence on parents, 
teachers or others without any independence, study consciousness. Once encounter difficulties, troubles, they will soon escape; they will be discouraged facing frustration, or even get bogged down to be pessimistic and world-weary or self-closed. In order to make students strong so as to overcome low-spirit arisen from setbacks, compressive and frustration, we should have the awareness of the importance by increasing the pressure education on students in the classroom combined with circuit theory teaching; from time to time, we should give more tests to students which might give the sense of pressure to them, and the harder questions and tests should be given, in line with the practice as possible, which might make students suffer a bit in the test, so as to see their own shortcomings. Of course, we should take those grades into account when assessing the whole achievement of students. After tests, simple summary and comment should be done that might help students find out troubleshooting for circuits, or get down to right direction of circuit theory courses learning, so that students may build up spiritual purposes and courage.

\section{The developing and cultivating of students' law-abiding thought and of students' self-disciplined shall be integrated into the circuit theory teaching process}

As a saying goes, "state has its laws, family own its rules", no rules, no manners. The aircraft should follow the flight lines, train should be along the track, of Mercedes Benz cars, should be in accordance with the road, people should follow the rules and legal constraints. Imagine an out-law without self-disciplined, without constraint entering a well-specified, legally binding society, what will happen? Obviously the guy cannot adapt to the society, not to mention the establishment and the surviving. So in the teaching process of circuit theory, the instructors should join the cultivation of students' autonomy ability, law-abiding thought to this link. The concrete procedure is added and the attendance record is also involved in the achievement of students as parts of the total grades. In doing these, we have assumed the responsibilities for the students, for the parents, which shall exercise the constraints and produce the effects on behaves of students.

\section{The developing and cultivating of students' fair competition consciousness shall be penetrated into the circuit theory teaching}

In the assessment of circuit theory course, except that the final examination shall be concurrent (the so called "same-time-test"), and the tests should be graded with streamlined method, the authors firmly believe that usual results should be worked by the students themselves. To fulfill the objects of fairness, justice and openness, promote the students' autonomous learning ability and personality development, the interference of human factors shall be eliminated, which will enable the students, through this education procedures, to enhance the sense of fair competition, seeing social bright future and the positive aspects as well. Although we study not for scores, it happens that scores and achievement often determine many personal interests and benefits as of a student, such as scholarships, graduated-student recommendation, looking for jobs etc.. To achieve fairness, justice, openness, usually the routine results should be assessed with relatively fair approaches adopted and accepted both by most of teachers and students. For example, at the school authors work with, in the past three years, each student annually circuit theory course was graded and assessed, the method used to decide the routine achievements and the final grades is as follow:

The original routine achievements $=$ (The total average scores from operations /assignments + Attendance record + The sum of $n$ tests results $\times 2+$ The experimental results $\times 2+$ Course paper grades or small course-design grade $\times 2) \div(2 n+6)$

Because the different teachers teaching this course has different standards in grading and correcting the homework, the midterm exam, attendance, small design courses, experiments and other aspects, the deviation is unavoidable, so to be fair, the original routine achievements should be listed from high to low order, and come out with the final routine achievements evaluated according to proportion in the following table and by the score orders from high to low. 


\begin{tabular}{|c|c|c|}
\hline $\begin{array}{l}\text { The scores ranges of } \\
\text { final routine } \\
\text { achievements }\end{array}$ & $\begin{array}{l}\text { Proportions } \\
\text { (The numbers= Four to } \\
\text { five homes in rounding) }\end{array}$ & Remarks \\
\hline $90 \sim 95$ & $10 \%$ & \multirow{5}{*}{$\begin{array}{l}\text { In every } 1 \text { point } \\
\text { must have some students, } \\
\text { and the individual } \\
\text { numbers should be as } \\
\text { uniform as possible. }\end{array}$} \\
\hline 85 89 & $15 \%$ & \\
\hline $80 \sim 84$ & $25 \%$ & \\
\hline $75 \sim 79$ & $25 \%$ & \\
\hline $70 \sim 74$ & $15 \%$ & \\
\hline below 70 points & $10 \%$ & Do not require uniform. \\
\hline
\end{tabular}

The final grades $=$ final routine achievements $\times 40 \%+$ scores of final examination $\times 60 \%$ 。

\section{Conclusion}

Practice has proved that, using the teaching process and approaches mentioned, not only enable students to better grasp the basic knowledge and basic principles of circuit theory, but also enable the students to improve the practical, innovation, and hand-operation abilities, enhance their personal qualities, which, for sure in the coming future, will make students more self-confident, give them the abilities to adapt to society better, integrate into the society more easily and faster.

\section{Acknowledgements}

This work was financially supported by the 2013 key projects of Guangxi higher education teaching reform project (2013JGZ101), the Academic Research Project of Guangxi Education Department (2013YB015), the laboratory construction and experimental teaching reform projects of Guangxi university (20120202).

\section{References}

[1] Wei Dongmei, Wu Jiekang, Li Ze. Set up the status quo and innovation of traditional teaching practice curriculum "circuit theory" room [J]. China power education,2009,6:73-74.

[2] Wei Dongmei, Li Ze, Huang Yang, Week Award, Liang Binghong. "Evaluation method of electrical engineering" curriculum reform and practice of [J]. China power education,2011,12: 170-171.

[3] Li Ze, Wang Jufeng, Wei Dongmei, Molik, Cai Yiming, Yang Daliang. Research and practice of innovative education base for electrical engineering students innovative talents -- education base construction of modular training scheme design of [J]. Chinese power education,2010, 30: 18-23.

[4] Li Ze, Wang Jufeng, Wei Dongmei, Molik, Cai Yiming, Yang Daliang. Research and practice -Innovative Practice for students innovative education base for electrical engineering students construction management, organization, guidance and evaluation of [J]. China power education,2010, 31: 108-109. 